\title{
Expanding relevance of aortic valve repair-is earlier operation indicated?
}

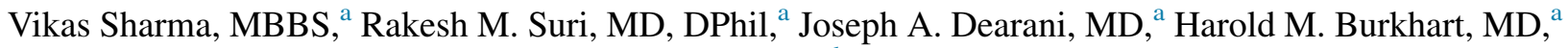 \\ Soon J. Park, MD, ${ }^{\mathrm{a}}$ Lyle D. Joyce, MD, ${ }^{\mathrm{a}}$ Zhuo Li, MSc, ${ }^{\mathrm{b}}$ and Hartzell V. Schaff, MD ${ }^{\mathrm{a}}$
}

Objectives: To define the durability of aortic valve repair $\left(\mathrm{AVR}_{\mathrm{ep}}\right)$ and the effect of surgical timing on late survival.

\begin{abstract}
Methods: From June 1986 to June 2011, 331 patients underwent elective AVR $_{\text {ep }}$ for aortic regurgitation (mean age, $53 \pm 17$ years; $76 \%$ men). The repair methods included commissuroplasty $(\mathrm{n}=270 ; 81 \%$ ), triangular resection and plication $(n=106 ; 32 \%)$, resuspension or cusp shortening $(n=102 ; 31 \%)$, and perforation closure $(\mathrm{n}=23 ; 7 \%)$.

Results: In-hospital mortality was $0.6 \%$ (2 of 332). Four patients (1\%) experienced early repair failure; two underwent repeat repair. Overall survival was $91 \%$ and $81 \%$ at 5 and 10 years, respectively. After adjusting for age, greater left ventricular end-systolic dimension (per $5 \mathrm{~mm}$; hazard ratio [HR], 1.49; 95\% confidence interval $[\mathrm{CI}], 1.23-1.79 ; P<.001$ ) and lower ejection fraction (per 5\%; HR, 1.42; 95\% CI, 1.25-1.63; $P \leq .001)$ were significant predictors of long-term mortality. Patients with ejection fraction $<50 \%$ and left ventricular end-systolic dimension $>50 \mathrm{~mm}$ had significantly greater odds of late death (HR, 3.46; $95 \%$ CI, 2.05-5.82; $P<.001$ and HR, 2.08; 95\% CI, 1.05-4.12; $P=.036$, respectively). The risk of aortic valve reoperation was $10 \%$ and $21 \%$ at 5 and 10 years, respectively. The presence of severe aortic regurgitation (HR, 2.2; 95\% CI, 1.1-5.06; $P=.02$ ) and more than mild regurgitation at discharge (HR, 5.87; 95\% CI, 2.67-12.68; $P \leq .0001)$ were predictors of late reoperation. Freedom from other valve-related events was $94 \%$ and $91 \%$ at 5 and 10 years, respectively. Forty-seven patients $(21 \%)$ with intact valve repair were using warfarin at the last follow-up visit.
\end{abstract}

Conclusions: $\mathrm{AVR}_{\mathrm{ep}}$ can be performed with excellent late survival and freedom from valve-related events. Awaiting the onset of ventricular dysfunction increases the risk of late mortality, warranting earlier consideration of $\mathrm{AVR}_{\mathrm{ep}}$ for patients with suitable anatomy. (J Thorac Cardiovasc Surg 2014;147:100-8)

The preferred surgical intervention and timing of therapy for significant aortic valve regurgitation (AR) continue to be debated. ${ }^{1}$ Historically, aortic valve replacement (AVR) has been the default procedure for the surgical management of

From the Division of Cardiovascular Surgery ${ }^{\mathrm{a}}$ and Department of Biomedical Statistics and Informatics, ${ }^{\mathrm{b}}$ Mayo Clinic College of Medicine, Rochester, Minn.

The Division of Cardiovascular Surgery, Mayo Clinic College of Medicine, funded the present study, including the statistical analysis.

Disclosures: The Division of Cardiovascular Surgery has a research grant titled "Randomized biological aortic valve replacement" funded equally by Edwards LifeSciences, St Jude Medical, and the Sorin Group. Dr Suri is the Principal Investigator for the PERCEVAL ${ }^{\mathrm{TM}}$ Investigational Device Exemption trial funded by the Sorin Group. Dr Park has served on the advisory board of Thoratec and as the course director for a Cleveland Clinic conference. None of the disclosures pertain to the current investigation. All other authors have nothing to disclose with regard to commercial support.

Read at the 93rd Annual Meeting of The American Association for Thoracic Surgery, Minneapolis, Minnesota, May 4-8, 2013.

Received for publication May 5, 2013; revisions received July 15, 2013; accepted for publication Aug 1, 2013; available ahead of print Sept 30, 2013.

Address for reprints: Rakesh M. Suri, MD, DPhil, Division of Cardiovascular Surgery, Mayo Clinic College of Medicine, 200 First St SW, Rochester, MN 55905 (E-mail: suri.rakesh@mayo.edu).

$0022-5223 / \$ 36.00$

Copyright (c) 2014 by The American Association for Thoracic Surgery

http://dx.doi.org/10.1016/j.jtcvs.2013.08.015 aortic valve disease, with repair techniques heterogeneously and infrequently used in those with isolated AR. ${ }^{2,3}$ During the past decade, experience with aortic valve repair $\left(\mathrm{AVR}_{\mathrm{ep}}\right)$ has expanded, driven in part by improvements in the echocardiographic delineation of cusp anatomy, the quantification of anatomic abnormalities, and consequent to an increasing facility with valve-sparing root replacement among cardiac surgeons. The impetus to develop and propagate valvuloplasty strategies for isolated AR in the absence of calcific stenosis was founded on the belief that $\mathrm{AVR}_{\mathrm{ep}}$ would offer significant advantages to patients in a manner analogous to mitral valve repair by avoiding prosthesis-related complications such as mismatch, endocarditis, thromboembolism, and early device senescence. ${ }^{4}$ An improved understanding of normal aortic root geometry and critical elements of functional aortic cusp coaptation has also facilitated the evolution of $\mathrm{AVR}_{\mathrm{ep}}$, in particular, for those with isolated valve abnormalities in the absence of aortic root dilation. ${ }^{5}$

Despite an increasing familiarity with $\mathrm{AVR}_{\mathrm{ep}}$ techniques and the availability of retrospective outcome data, ${ }^{6-8}$ the predictors of survival and reoperation risk after isolated $\mathrm{AVR}_{\mathrm{ep}}$ remain unclear, particularly in relation to the 


\section{Abbreviations and Acronyms \\ $\mathrm{AR}=$ aortic regurgitation \\ AVR = aortic valve replacement \\ $\mathrm{AVR}_{\mathrm{ep}}=$ aortic valve repair \\ $\mathrm{CI}=$ confidence interval \\ $\mathrm{EF} \quad=$ ejection fraction \\ HR = hazard ratio \\ LVESD = left ventricular end-systolic dimension}

effect of surgical timing. We thus sought to explore the long-term outcomes of isolated $\mathrm{AVR}_{\mathrm{ep}}$ in the absence of aortic root dilation or dissection and, also, to test the hypothesis that the timing of repair for isolated AR might affect long-term survival postoperatively.

\section{METHODS}

After institutional review board approval, we identified consecutive patients who had undergone $\mathrm{AVR}_{\mathrm{ep}}$ for significant AR from June 1986 to June 2011 in the Mayo Clinic Adult Cardiac Surgical Database. All patients provided written informed consent for the study. We excluded those with AR associated with acute or chronic aortic dissection or ventricular septal defect and patients with aortic root dilation and moderate to severe AR who had undergone aortic valve-sparing aortic sinus wall replacement $(\mathrm{n}=113)$ to specifically address the subset of patients with significant AR related to the aortic valve cusps or annulus $(n=331)$. A retrospective review of the medical records was performed.

All patients underwent surgical treatment of the aortic valve according to current North American guidelines, with either the presence of symptoms or left ventricular dysfunction. ${ }^{1}$ Of the patients, $196(59 \%)$ had severe AR preoperatively. Other indications included the existence of subsevere AR in patients undergoing concomitant surgery for severe mitral regurgitation or coronary artery revascularization. Intraoperative transesophageal echocardiography was routinely used, focusing on the cusp anatomy, mechanism of AR, and AR jet (eccentric or central) and to judge the adequacy of valve repair. All patients also underwent repeat echocardiography at discharge from the hospital.

The patients were categorized into 4 groups: group 1, annular dilation without cusp prolapse $(\mathrm{n}=77 ; 23 \%)$; group 2 , bicuspid aortic valve $(\mathrm{n}=133 ; 41 \%)$, further divided into those with $(\mathrm{n}=99)$ and without $(\mathrm{n}=34)$ a thickened raphe; group 3 , tricuspid aortic valve with cusp prolapse $(\mathrm{n}=96,29 \%)$; and group 4 , cusp perforation $(\mathrm{n}=23 ; 6 \%)$. Two patients underwent minor shaving and/or debridement of a cusp because of restricted valve mobility.

\section{Operative Techniques}

Identification of cusp prolapse or restriction was facilitated by examining the cusp motion and comparing the position of the free margin to a reference coaptation point at the height of the free margin of the normal cusp. ${ }^{9}$ If 2 cusps were prolapsing, the nonprolapsing cusp was used as the reference. Rarely, if all 3 cusps had prolapsed, we attempted to restore coaptation to well above the annular plane at the mid-sinus level. Excess motion and an elongated free margin length were also frequently observed. Restriction was recognized by the presence of reduced cusp motion. All procedures were performed through a full or minimedian sternotomy with cardiopulmonary bypass and central cannulation. Repair for annular dilation was accomplished by subcommissural annuloplasty (or "commissuroplasty"). It was performed by placement of pledgeted, horizontal mattress stitches with 3-0 or 4-0 braided polyester suture through the aortic wall at each commissure to narrow the angle of the subcommissural triangles, thereby reducing the circumference of the annulus and increasing the surface area of cuspal coaptation (Figure 1, $A$ ). ${ }^{10}$ In most patients with bicuspid aortic valve disease, regurgitation was caused by retraction and/or prolapse of the conjoint cusp. The most frequent anatomic finding was a conjoint cusp beneath the right and left coronary sinuses. Such bicuspid valves were repaired using limited triangular resection and suture reconstruction of the median raphe with 5-0 or 6-0 polypropylene suture (Figure 1, B). This maneuver shortened and elevated the free edge of the cusp, increasing the area of coaptation and permitting apposition with the noncoronary cusp. In a few patients with pliable and nonrestricted cusps, prolapse of the conjoint or the noncoronary cusp was corrected using simple mid-cuspal plication sutures without resection (Figure 1, B). Subcommissural annuloplasty was combined with cusp repair when indicated. Regurgitation of the tricuspid aortic valves because of prolapse of $\geq 1$ cusps was frequently treated using cusp plication, either centrally or near the commissure with 5-0 polypropylene suture, ${ }^{11}$ or resuspension of the free edge of the cusp by weaving a 5-0 polytetrafluoroethylene suture along the free edge and anchoring it through the aortic wall (Figure $1 C$ ). Cusp perforation resulting from infective endocarditis or iatrogenic injury was repaired by patch closure using pericardium secured with interrupted or continuous 6-0 polypropylene suture (Figure 1,D).

\section{Follow-up}

Clinical follow-up was conducted through outpatient visits or by mailed questionnaire. Information on survival status, valve-related complications, including thromboembolism and endocarditis, and reoperation were obtained from the clinical records, by telephone interviews, and from the Social Security Death Index. Transthoracic echocardiography was obtained in $89 \%$ of the surviving patients. The mean follow-up duration was $5.75 \pm 4.75$ years and was available for 302 of the 328 hospital survivors $(92 \%)$.

\section{Statistical Analysis}

Descriptive statistics for categorical variables are reported as frequencies and percentages and continuous variables as the mean \pm standard deviation or median and range, as appropriate. Kaplan-Meier analyses were used to create survival curves and calculate the 5-, 10-, and 15-year survival and freedom from reoperation statistics. Cox regression models were used to determine univariate and/or multivariate predictors of late mortality and reoperation. The multivariate model considered the univariate significant variables $(P<.05)$, with model selection using the stepwise method (backward and forward methods resulted in the same model). Late survival was compared using an age- and gender-matched general population using the 1-sample log-rank test. All statistical tests were 2-sided, with the $\alpha$ level set at 0.05 for statistical significance.

\section{RESULTS \\ In-Hospital Outcomes}

The mean age was $53 \pm 17$ years (median, 54; range, 15-89). Of the 331 patients, 254 were men (76\%) and 77 were women $(24 \%)$. The most common presenting symptoms were fatigue, palpitations, and shortness of breath. A total of 103 patients $(31 \%)$ had New York Heart Association class III-IV symptoms preoperatively. Patients with bicuspid valves were younger and had fewer coexisting medical conditions than those with tricuspid aortic valve anatomy (Table 1). The mean crossclamp and cardiopulmonary time was $32 \pm 17$ minutes and $44 \pm 21$ minutes for isolated $\mathrm{AVR}_{\mathrm{ep}}$, respectively. Concomitant procedures were performed in 180 patients $(54 \%)$. The most common 

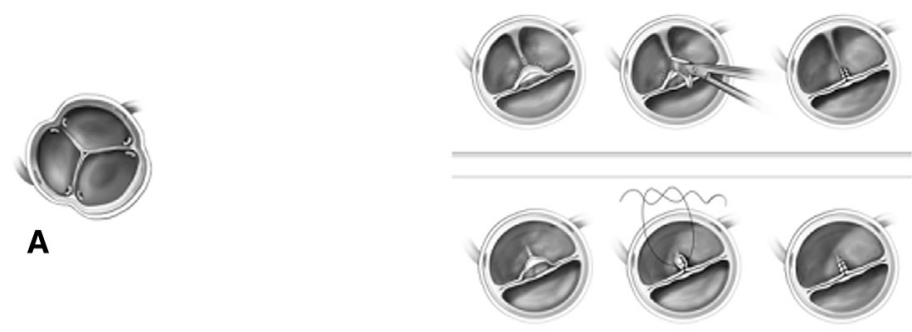

$\mathbf{B}$
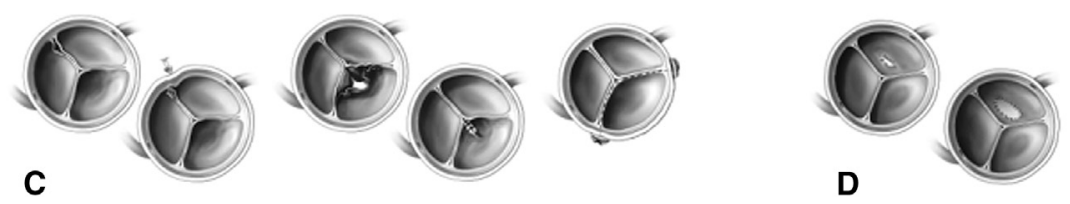

FIGURE 1. Aortic valve repair techniques. A, Annular dilation of aortic valve causing central regurgitation. Plication stitches are placed in the aortic wall at each commissure. B, Bicuspid aortic valve. Triangular resection of the conjoint cusp raphe is performed and then reconstructed using monofilament suture, with mid-cusp plication of prolapsing bicuspid aortic valve cusp without raphe. C, Tricuspid valve with prolapse. Central plication or Trusler stitch or free edge resuspension can be used. D, Patch repair of perforation.

associated operations were mitral valve repair $(\mathrm{n}=66$, $36 \%)$, coronary artery bypass grafting $(n=47,26 \%)$, and replacement of the dilated tubular portion of the ascending aorta $(\mathrm{n}=38,21 \%$; Table 2$)$.

A second cardiopulmonary bypass run was necessary in 11 patients $(3 \%)$ to correct residual AR. Two early deaths $(0.6 \%)$ occurred: an 80 -year-old man, who had undergone aortic and mitral valve repair, coronary artery bypass grafting, and extended left ventricular septal myectomy, and a 76-year-old woman, who had undergone aortic and tricuspid valve repair with mitral valve replacement. No deaths occurred in the bicuspid $\mathrm{AVR}_{\mathrm{ep}}$ subgroup. Four patients $(1 \%)$ underwent aortic valve reoperation during the index admission. In each patient, the routine predischarge echocardiogram identified significant AR compared with the intraoperative echocardiogram. All 4 patients had dehiscence of the plication sutures noted. Repeat repair by plication was possible in 2 patients, and 2 patients required valve replacement because the remaining tissue quality was suboptimal.

\section{Late Survival}

There were 58 late deaths. Of these, $17(29 \%)$ were cardiovascular related and $16(28 \%)$ were not; in 25 patients $(43 \%)$, the cause of death was unknown. Overall, late survival at 5,10 , and 15 years was $91 \%, 80 \%$, and $58 \%$, respectively, and was statistically indistinguishable from a comparable age- and gender-matched population $(P=.52$; Figure 2, A). The corresponding estimated freedom from known cardiac-related death was $98 \%, 95 \%$, and $91 \%$.

TABLE 1. Patient demographics

\begin{tabular}{|c|c|c|c|c|}
\hline Preoperative characteristics & Total $(\mathbf{n}=\mathbf{3 3 1})$ & Tricuspid $(n=198)$ & Bicuspid $(n=133)$ & $P$ value \\
\hline Age (y) & $53 \pm 17$ & $61 \pm 15$ & $42 \pm 14$ & $<.001$ \\
\hline Male gender & $251(76)$ & $138(70)$ & $116(87)$ & NS \\
\hline NYHA class III-IV & $103(31)$ & $81(39)$ & $22(17)$ & $<.001$ \\
\hline Smoking & $81(24)$ & $48(24)$ & $33(26)$ & NS \\
\hline Hypertension & $136(41)$ & $98(48)$ & $38(30)$ & $<.001$ \\
\hline Diabetes mellitus & $29(9)$ & $20(10)$ & $9(8)$ & NS \\
\hline Connective tissue disorders & $11(3)$ & $10(5)$ & $1(0.7)$ & $<.01$ \\
\hline Previous MI & $21(6)$ & $20(9)$ & $1(0.7)$ & $<.001$ \\
\hline Previous cardiac surgery & $13(4)$ & $12(6)$ & $1(0.7)$ & $<.001$ \\
\hline Atrial fibrillation & $64(19)$ & $52(26)$ & $12(9)$ & $<.001$ \\
\hline $\operatorname{LVEF}(\%)$ & $59 \pm 8$ & $59 \pm 7$ & $61 \pm 9$ & NS \\
\hline Preoperative severe AR & $196(59)$ & $97(49)$ & $99(74)$ & $<.001$ \\
\hline $\operatorname{LVESD}(\mathrm{mm})$ & $39 \pm 8$ & $38 \pm 8$ & $39 \pm 8$ & .014 \\
\hline $\operatorname{LVEDD}(\mathrm{mm})$ & $59 \pm 9$ & $58 \pm 9$ & $60 \pm 9$ & .001 \\
\hline Associated major cardiac procedures & 258 & $132(66)$ & $41(30)$ & $<.001$ \\
\hline
\end{tabular}

Data presented as mean \pm standard deviation or n (\%). NS, Not significant; $N Y H A$, New York Heart Association; $M I$, myocardial infarction; $L V E F$, left ventricular ejection fraction; $A R$, aortic regurgitation; $L V E S D$, left ventricular end-systolic dimension; $L V E D D$, left ventricular end-diastolic dimension. 
TABLE 2. Intraoperative and postoperative data

\begin{tabular}{lc}
\hline \multicolumn{1}{c}{ Variable } & Value \\
\hline Cardiopulmonary bypass time (min) & \\
Total $(\mathrm{n}=331)$ & $60 \pm 30$ \\
Isolated $\mathrm{AVR}_{\mathrm{ep}}(\mathrm{n}=123)$ & $46 \pm 21$ \\
Crossclamp time $(\mathrm{min})$ & \\
Total $(\mathrm{n}=331)$ & $44 \pm 21$ \\
Isolated AVR ep $\left._{\text {( }} \mathrm{n}=123\right)$ & $32 \pm 17$ \\
Major associated procedures & $180(78)$ \\
Mitral valve repair & 60 \\
Mitral replacement & 6 \\
Coronary artery bypass grafting & 47 \\
Ascending aorta replacement & 38 \\
Septal myectomy & 13 \\
TV procedure & 8 \\
Other & 8 \\
Operative techniques & \\
Commissural plication & $270(81)$ \\
Partial cusp resection with plication & $106(32)$ \\
Resuspension or cusp shortening & $102(31)$ \\
Cusp perforation closure & $23(7)$ \\
Cusp shaving & $35(10)$ \\
Early AV reintervention & $4(1)$ \\
Repeat repair & $2(0.5)$ \\
Replacement & $2(0.5)$ \\
Postoperative outcomes & \\
Early death & $2(0.5)$ \\
Bleeding & $8(2.4)$ \\
CVA & $6(1.8)$ \\
Prolonged ventilation & $9(2.6)$ \\
\hline Data presented as mean \pm standard deviation or $\mathrm{n}(\%) . T V$, Tricuspid valve; & $A V$, aortic \\
valve; $C V A$, cerebrovascular accident; $A V R_{e p}$, aortic valve repair. & \\
&
\end{tabular}

We next sought to establish the determinants of late mortality. Univariate analysis demonstrated the following preoperative variables as significant predictors: New York Heart Association class III-IV symptoms (hazard ratio $[\mathrm{HR}], 1.88 ; 95 \%$ confidence interval [CI], 1.12-3.17; $P=.02)$, larger left ventricular end-systolic dimension (LVESD; per $5 \mathrm{~mm}$; HR, 1.51; 95\% CI, $1.25-1.82 ; P \leq .001)$, poorer left ventricular ejection fraction (EF; per 5\%; HR, 1.42; 1.25-1.63; $P \leq .001$ ), older age (HR, 1.06; 95\% CI, 1.04-1.08; $P=.001$ ), and nonbicuspid aortic valve anatomy (HR, 5.0; 95\% CI, 2.08-11.0; $P=.001)$. To determine which of these factors independently influenced late mortality, multivariate analysis was performed. The overall model revealed that larger LVESD (per $5 \mathrm{~mm}$; HR, 1.49; 95\% CI, 1.23-1.79; $P<.001)$ and older age (HR, 1.06; 95\% CI, 1.04-1.08; $P=.001$ ) were independently associated with diminished late survival (Table 3). Additional exploratory modeling revealed that LVESD and EF correlated negatively $(r=-0.6 ; P<.001)$; hence, when LVESD was removed from the model, a decreased preoperative EF (per 5\%; HR, 0.76; 95\% CI, 0.66-0.87; $P<.001)$ was a significant predictor of improved late survival, along with older age. The risk of late death was 3.5 -fold greater in those with a preoperative EF of $<50 \%$ (HR, 3.46; 95\% CI, 2.05-5.82; $P<.001$; Figure $2, B$ ) and 2-fold greater in patients with a preoperative LVESD > $50 \mathrm{~mm}(\mathrm{HR}, 2.08$; 95\% CI, 1.05-4.12; $P=.04$; Figure 2,C). Also, the survival of patients with $\mathrm{EF}<50 \%$ and LVESD $>50 \mathrm{~mm}$ was significantly worse than that in the age- and gender-matched controls ( $P=.004$ and $P=.005$, respectively).

A subgroup analysis of patients with severe AR preoperatively as the predominant cause for cardiac operation, who did not require other major associated cardiac surgical procedures, revealed survival of $92 \%$ and $85 \%$ at 5 and 10 years, respectively. A poorer preoperative $\mathrm{EF}$ (per $5 \%$; HR, 0.62; 95\% CI, 0.48-0.81; $P<.001)$ and larger LVESD (per $5 \mathrm{~mm}$; HR, 2.65; 95\% CI, 1.62-4.3; $P \leq .001$ ) were, again, both significant predictors of late mortality after adjustment for age.

\section{Late Reoperation}

Of the 331 patients, $44(13 \%)$ required AVR during the follow-up period. However, the primary indication for late reoperation was severe $\mathrm{AR}$ and/or stenosis in only 40 patients $(12 \%$; group $1, \mathrm{n}=10$; group $2, \mathrm{n}=13$; group $3, \mathrm{n}=16$; and group $4, \mathrm{n}=1$ ). No difference was found in the need for late aortic valve reoperation among the 4 anatomic groups $(P=.66)$. The most common causes of recurrent $\mathrm{AR}$ identified at reoperation were scarring and calcification of the aortic valve $(\mathrm{n}=17)$, recurrent dilation and central regurgitation $(\mathrm{n}=13)$, recurrent prolapse $(\mathrm{n}=4)$, perforation at the repair site $(\mathrm{n}=3)$, and unknown $(\mathrm{n}=3)$. The median interval between the initial operation and late aortic valve reoperation was 3.9 years (range, 9 months to 15.6 years) overall. Freedom from late aortic valve reoperation was $90 \%, 79 \%$, and $72 \%$ at 5,10 , and 15 years, respectively (Figure 2, D). The presence of severe preoperative AR (HR, 1.99; 95\% CI, 1.03-3.85; $P=.04$ ) and more than mild AR at discharge (HR, 5.87; $95 \% \mathrm{CI}$, 2.67-12.68; $P \leq .0001$ ) were significant predictors of late reoperation.

In a subgroup analysis of patients with severe AR, 30 patients $(15 \%)$ needed AVR (group $1, \mathrm{n}=6,21 \%$; group $2, \mathrm{n}=12,11 \%$; group $3, \mathrm{n}=11,23 \%$; group $4, \mathrm{n}=1$, $7 \%$ ). Freedom from late aortic valve reoperation was $88 \%, 74 \%$, and $67 \%$ in the severe AR group at 5,10 , and 15 years, respectively.

\section{Echocardiographic Follow-up}

Follow-up echocardiograms were available for 205 patients with intact valve repair $(89 \%$ of the surviving patients) and revealed freedom from late AR grade $>2+$ of $88 \%, 75 \%$, and $58 \%$ (Figure $2, E$ ) in the overall group and $86 \%, 71 \%$, and $54 \%$ in patients with severe AR at 5 , 10 , and 15 years, respectively. 

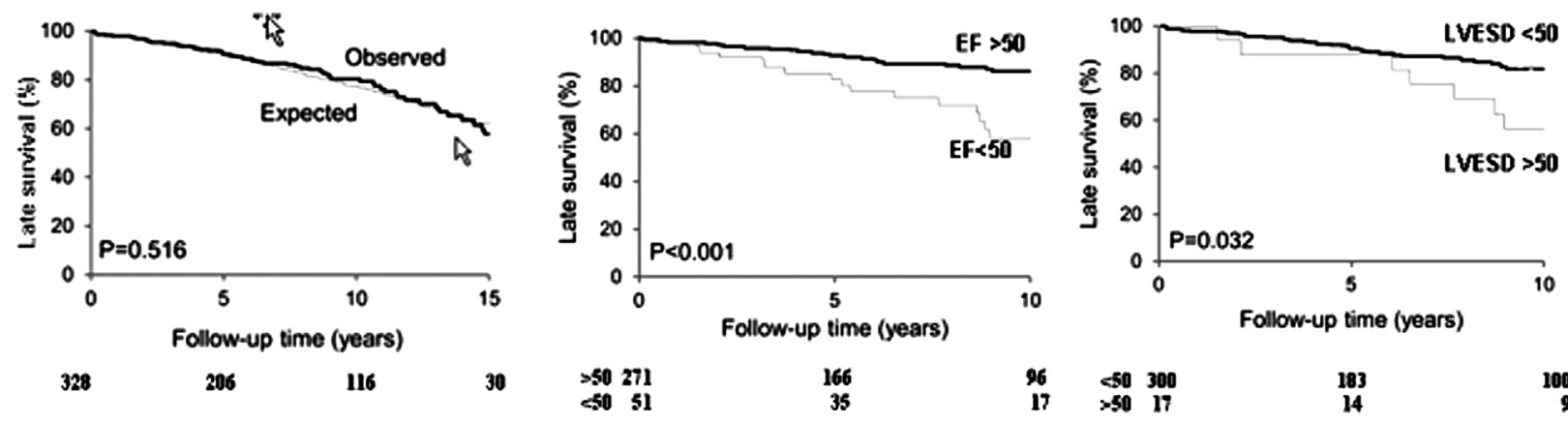

A

B

C
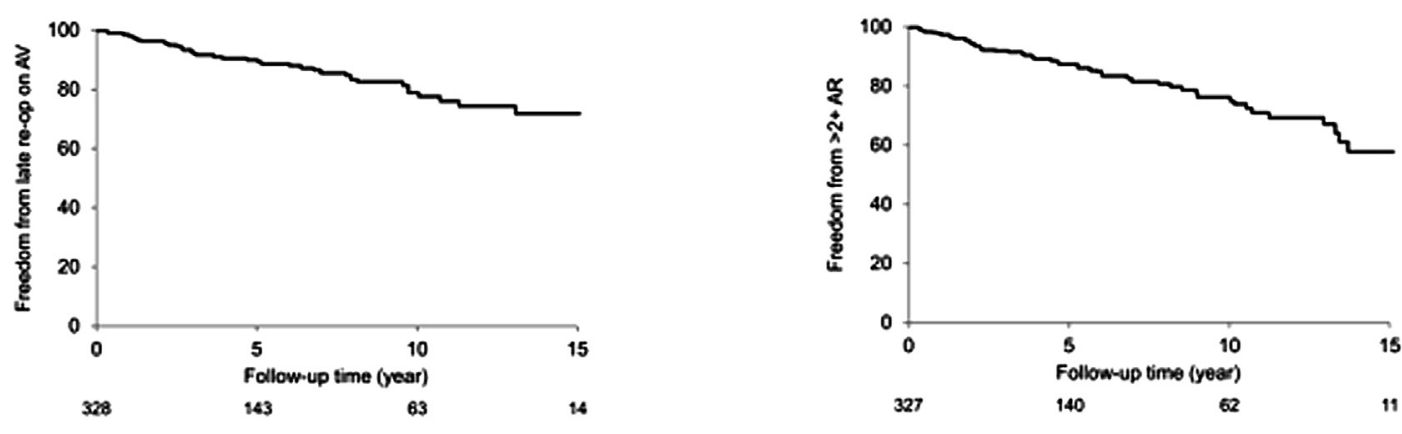

D

E

FIGURE 2. A, Kaplan-Meier curve detailing late survival compared with healthy age- and gender-matched US population. B, Kaplan-Meier curves for survival for patients with ejection fraction $(E F)<50 \%$ and $>50 \%$. C, Kaplan-Meier curves for survival for patients with left ventricular end-systolic dimension $(L V E S D)<50$ and $>50 \mathrm{~mm}$. D, Kaplan-Meier curve for freedom from late aortic valve $(A V)$ reoperation (re-op). E, Kaplan-Meier curve for freedom from aortic regurgitation $(A R)$ grade $>2+$.

\section{Valve-Related Complications}

Of the 271 late survivors, $71(26 \%)$ were receiving warfarin prophylaxis for various reasons, including atrial fibrillation in 37, mechanical aortic or mitral prosthesis in 24 , a history of stroke in 7 , or deep vein thrombosis in 3 . In contrast, only $47(21 \%)$ of the patients with intact $A_{V R}$ ep required warfarin at the last follow-up examination. During the follow-up period, 10 embolic events (2 transient ischemic attacks and 8 strokes) and 10 gastrointestinal bleeding events (all patients receiving warfarin) occurred. One patient developed endocarditis, which was medically managed. Freedom from valve-related events (ie, stroke, bleeding, and endocarditis) was $95 \%, 92 \%$, and $87 \%$ and $97 \%, 95 \%$, and $91 \%$ for the isolated $\mathrm{AVR}_{\mathrm{ep}}$ group at 5,10 , and 15 years, respectively. The anatomic groupstratified incidence of valve-related events is listed in Table 4.

\section{DISCUSSION}

During the past 20 years, marked progress has been made in the understanding of the functional anatomy of the aortic valve, including a greater appreciation of the interrelationship between the aortic cusps and sinuses of Valsalva. ${ }^{5,7,12}$ Although an increasing body of evidence supports the

TABLE 3. Univariate and multivariate predictors of late mortality

\begin{tabular}{|c|c|c|c|c|}
\hline \multirow[b]{2}{*}{ Variable } & \multicolumn{2}{|c|}{ Univariate predictors } & \multicolumn{2}{|c|}{ Multivariate predictors } \\
\hline & HR $(95 \%$ CI $)$ & $P$ value & HR $(95 \%$ CI $)$ & $P$ value \\
\hline Age & $1.06(1.04-1.08)$ & $<.001$ & $1.06(1.04-1.08)$ & $<.001$ \\
\hline Bicuspid valve & $0.20(0.09-0.48)$ & $<.001$ & & \\
\hline NYHA class III-IV & $1.88(1.12-3.17)$ & $<.001$ & & \\
\hline $\mathrm{EF}$ (5\% increase) & $0.7(0.61-0.81)$ & $<.001$ & $0.76(0.66-0.87)^{*}$ & $<.001$ \\
\hline LVESD (5-mm increase) & $1.15(1.09-1.22)$ & $<.001$ & $1.49(1.23-1.79)$ & $<.001$ \\
\hline $\mathrm{EF}<50 \%$ & $3.46(2.05-5.82)$ & $<.001$ & & \\
\hline LVESD $>50 \mathrm{~mm}$ & $2.08(1.05-4.12)$ & .036 & & \\
\hline
\end{tabular}

$H R$, Hazard ratio; $C I$, confidence interval; NYHA, New York Heart Association; $E F$, ejection fraction; LVESD, left ventricular end-systolic dimension. *Excluding LVESD 
TABLE 4. Valve-related events (group-wise distribution)

\begin{tabular}{|c|c|c|c|c|}
\hline Variable & $\begin{array}{c}\text { Group 1 } \\
\text { (annular dilation; } \mathbf{n}=\mathbf{7 7})\end{array}$ & $\begin{array}{c}\text { Group } 2 \\
\text { (bicuspid; } \mathbf{n}=\mathbf{1 3 3} \text { ) }\end{array}$ & $\begin{array}{c}\text { Group 3 } \\
\text { (tricuspid prolapse; } \mathbf{n}=96)\end{array}$ & $\begin{array}{c}\text { Group 4 } \\
\text { (perforation; } \mathbf{n}=\mathbf{2 3} \text { ) }\end{array}$ \\
\hline \multicolumn{5}{|l|}{ Reoperation } \\
\hline Total $(\mathrm{n}=40)^{*}$ & 10/77 (13) & $12 / 133(9)$ & 17/96 (18) & $1 / 23(4)$ \\
\hline Severe AR group $(\mathrm{n}=30)^{*}$ & $6 / 28(21)$ & $12 / 107(11)$ & $11 / 47(34)$ & $1 / 14(7)$ \\
\hline \multicolumn{5}{|l|}{ Interval to reoperation (y) } \\
\hline Mean \pm SD & $4.2 \pm 4$ & $6.5 \pm 4.5$ & $5.8 \pm 4$ & 4.99 \\
\hline Median (IQ, 25\%-75\%) & $2.6(1-7)$ & $7.7(1.3-9.7)$ & $5.3(2.6-8)$ & \\
\hline $\mathrm{AR}>2+(\mathrm{n}=50)^{*}$ & 13/77 (17) & $13 / 133(10)$ & $23 / 96(24)$ & $1 / 23(4)$ \\
\hline $\mathrm{AR}>2+(\text { severe AR group; } \mathrm{n}=36)^{*}$ & $6 / 28(21)$ & 13/107 (12) & $16 / 47(34)$ & $1 / 14(7)$ \\
\hline Death $(\mathrm{n}=58) \dagger$ & $23 / 77(28)$ & $6 / 133(5)$ & $25 / 66(26)$ & 4/23 (17) \\
\hline Valve-related events $(n=21)^{*}$ & 7/77 (9) & $5 / 133(4)$ & 9/96 (9) & 0 \\
\hline Warfarin $(\mathrm{n}=71)$ & 23/77 (30) & $21 / 133(16)$ & $23 / 96(24)$ & $4 / 23(17)$ \\
\hline
\end{tabular}

Data in parentheses are percentages. $A R$, Aortic regurgitation; $S D$, standard deviation; $I Q$, interquartile range. $* P>.05$. $\dagger P<.05$ for group 2 versus rest of groups.

performance of $\mathrm{AVR}_{\mathrm{ep}}$ at aortic root aneurysm surgery, the late outcome of isolated cup repair for severe AR has been less well described. Our large series of isolated $\mathrm{AVR}_{\mathrm{ep}}$ has detailed the safety of this operation, with very low overall early mortality $(0.6 \%)$, particularly for bicuspid aortic valve disease $(0 \%)$. The long-term outcomes of $\mathrm{AVR}_{\mathrm{ep}}$ were also excellent, with normalization of late survival to that of an age- and gender-matched population, along with rates of freedom from aortic valve-related events and reoperation comparable to those for biologic aortic valve substitutes. Importantly, patients who undergo $\mathrm{AVR}_{\mathrm{ep}}$ before the onset of left ventricular dilation $($ LVESD $<50 \mathrm{~mm})$ or dysfunction $(\mathrm{EF}>50 \%$ ) benefited from preservation of late survival. These data call for an earlier recognition of significant AR to facilitate prompt referral for surgical intervention in those with cusp anatomy suitable for valve repair.

The mean age of our present study cohort was 53 years (42 years for those with bicuspid disease). Thus, durability must be considered with reference to the early senescence of biologic AVR in young patients $^{13,14}$ in contrast to the greater durability of biologic AVR in older populations. ${ }^{15,16}$ Our previous report comparing bicuspid $\mathrm{AVR}_{\mathrm{ep}}$ versus bioprosthetic replacement revealed no significant differences in survival or reoperation at a mean follow-up of 5.1 years $(P<.12) .{ }^{17}$ Smedira and colleagues ${ }^{13}$ found that the instantaneous risk of explantation "accelerated exponentially" from $12(13 \%)$ to 19 years $(53 \%)$ after pericardial AVR in nonelderly patients. Chan and associates ${ }^{18}$ reported that the median interval to reoperation in patients undergoing AVR with the current generation stented aortic bioprostheses was 7.7 years in patients $<40$ years. The present results of $\mathrm{AVR}_{\mathrm{ep}}$ compared favorably, suggesting that repair is an acceptable alternative to biologic aortic valve substitutes in the current era, although a limiting factor might have been that both the clinical and echocardiographic follow-up was $89 \%$ complete.
The reoperation rates after $\mathrm{AVR}_{\mathrm{ep}}$ have been steadily declining because of the enhanced understanding of aortic valve physiology, predictors of repair failure (coaptation level, cusp height, and coaptation length), and standardization of repair techniques with the availability of classification schemes. Despite this progress, the practices of aortic and mitral valve repair differ in several important ways. First, the techniques of $\mathrm{AVR}_{\mathrm{ep}}$ have varied among centers. ${ }^{2}$ Second, tissue quality is critical to the technical feasibility and durability of $\mathrm{AVR}_{\mathrm{ep}}$ but is less frequently a concern in those with degenerative mitral disease. The presence of severe AR was a significant predictor for late aortic valve reoperation in the present series, which could suggest that pronounced cusp stretching might have led to some degree of tissue weakening. Third, the frequency of congenital bicuspid variations, particularly in young patients, might limit the routine application of standard repair techniques, thus influencing the frequency of $\mathrm{AVR}_{\mathrm{ep}}$. Finally, although it is rare to encounter deficient mitral valve leaflet tissue in the setting of degenerative mitral regurgitation, the same is not true of degenerative AR. The relative paucity of cusp surfaces available for reconstruction can, at times, preclude repair, particularly in the presence of cusp restriction, thickening, or fenestration.

The durability of $\mathrm{AVR}_{\mathrm{ep}}$ was statistically similar among the 4 anatomic groups in our analysis, just as was the late recurrence of $A R$ and the need for aortic valve reoperation. The homogeneity of durability outcomes was likely attributable to application of the lessons learned with $\mathrm{AVR}_{\mathrm{ep}}$ during the past 20 years at our center, including the systematic assessment of aortic valve pathologic features and valve-specific tailoring of the repair strategy. Most of the early data on bicuspid valve repair detailed a 10-year reoperation rate of approximately $\geq 20 \%$, primarily because of recurrent AR. ${ }^{19}$ Two recent reports by Aicher and colleagues ${ }^{20}$ and de Kerchove and colleagues ${ }^{21}$ have asserted that improvements in the durability of bicuspid 
$\mathrm{AVR}_{\mathrm{ep}}$ have been realized with the adoption of various annular reduction maneuvers. Although, we have not introduced these into our practice, we remain interested as long-term results emerge.

We propose that several patient subsets might benefit from enhanced efforts to offer $\mathrm{AVR}_{\mathrm{ep}}$. Despite the similar statistical durability of $\mathrm{AVR}_{\mathrm{ep}}$ among the 4 anatomic subgroups, our data can be interpreted as supportive of $\mathrm{AVR}_{\mathrm{ep}}$ for young patients with bicuspid AR, who had had numerically fewer reoperations and longer median interval to repair failure. Only $21 \%$ of $\mathrm{AVR}_{\text {ep }}$ patients with intact $\mathrm{AVR}_{\mathrm{ep}}$ required warfarin ( $6 \%$ with bicuspid repair alone), an appealing lifestyle-related benefit in those who are young, active, and of childbearing age. Second, nonelderly patients with tricuspid prolapse or aortic annular dilation could also benefit from AVR $\mathrm{ep}_{\mathrm{e}}$ instead of AVR, particularly those undergoing concomitant cardiac surgical procedures. Third, the presence of isolated cusp perforation related to healed endocarditis or iatrogenic injury might be associated with greater reproducibility of repair with numerically fewer reoperations, perhaps because a single element of the valvular-aortic complex was perturbed. In contrast, elderly patients with nonbicuspid- and nonperforationrelated AR might be less likely to realize a significant survival or durability-related benefit from $\mathrm{AVR}_{\mathrm{ep}}$ compared with bioprosthetic replacement.

The current consensus statements have recommended AVR for asymptomatic patients with AR when the EF is $<50 \%$ and/or the LVESD is $>55 \mathrm{~mm} .{ }^{1}$ Unlike the trend toward early surgery for asymptomatic, severe degenerative MR, a greater threshold exists before surgery will be recommended to treat severe AR, perhaps because these patients have historically required AVR. Additionally, young patients with AR often remain asymptomatic for many years, with normal left ventricular systolic function because of compensatory mechanisms. ${ }^{1}$ Concerning, however, is that the progression to asymptomatic left ventricular dysfunction is approximately $1.2 \%$ annually in patients with severe $\mathrm{AR}^{1}$; thus, by the time symptoms have developed, myocardial impairment might have increased the perioperative risk, including postoperative heart failure and death. ${ }^{22}$ Our presented data indicate that $\mathrm{AVR}_{\mathrm{ep}}$ is capable of restoring late patient survival to that of an age- and gender-matched population, supporting the assertion that early correction of severe AR before the onset of severe left ventricular dysfunction (LVESD $>50 \mathrm{~mm}$ or $\mathrm{EF}<50 \%$ ) is prudent. Similar findings were obtained in our previous study of patients with AR undergoing AVR, ${ }^{23}$ in whom larger indexed left ventricular systolic and diastolic dimensions were both associated with increased late mortality. Newer methods to assess myocardial function using cardiac magnetic resonance imaging, tissue Doppler imaging, or speckle tracking might play a future role in the decisions regarding the timing or $\mathrm{AVR}_{\mathrm{ep}}{ }^{24}$; however, the present data support a more aggressive stance in addressing chronic AR in those who are candidates for $\mathrm{AVR}_{\mathrm{ep}}$.

\section{Study Limitations}

The present study was a retrospective analysis spanning almost 20 years, during which, our techniques, approach, and intent to perform $\mathrm{AVR}_{\mathrm{ep}}$ have evolved. Although not the purpose of the present report, a future prospective trial comparing $\mathrm{AVR}_{\mathrm{ep}}$ and $\mathrm{AVR}$ in risk-matched young patients (age $<60$ years) would convey additional useful information capable of informing the decision to offer $\mathrm{AVR}_{\mathrm{ep}}$ versus AVR. The exclusion of patients with aortic sinus and/or root pathologic features or those otherwise undergoing aortic root surgery could be challenged by those who believe that annular stabilization maneuvers performed during aortic valve reimplantation are important. However, aortic valve reimplantation for $\mathrm{AR}$ in the absence of aortic root dilation has not been routinely used at Mayo Clinic to date.

\section{CONCLUSIONS}

$\mathrm{AVR}_{\mathrm{ep}}$ for significant AR can be performed with near $0 \%$ early mortality, normalizing late survival and offering good durability. The low incidence of valve-related complications and infrequent requirement for anticoagulation make $\mathrm{AVR}_{\mathrm{ep}}$ an attractive option, particularly for young patients with thin, pliable, and mobile aortic cusps and those with bicuspid configuration. Early referral for $\mathrm{AVR}_{\mathrm{ep}}$ for patients with suitable anatomy should be performed before the onset of left ventricular dilation or dysfunction to optimize long-term survival.

We would like to express our gratitude to Judy Lenoch for her help with the database analysis. We would also like to thank Michael A. King, Media Division, for his help in the preparation of illustrations.

\section{References}

1. Bonow RO, Carabello BA, Chatterjee K, de Leon AC Jr, Faxon DP, Freed MD, et al. 2008 Focused update incorporated into the ACC/AHA 2006 guidelines for the management of patients with valvular heart disease: a report of the American College of Cardiology/American Heart Association Task Force on Practice Guidelines (Writing Committee to revise the 1998 guidelines for the management of patients with valvular heart disease). Endorsed by the Society of Cardiovascular Anesthesiologists, Society for Cardiovascular Angiography and Interventions, and Society of Thoracic Surgeons. J Am Coll Cardiol. 2008; 52:e1-142.

2. Boodhwani M, El Khoury G. Aortic valve repair: a glimpse into the future. Eur J Cardiothorac Surg. 2012;41:2-3.

3. Aicher D, Schäfers HJ. Aortic valve repair-current status, indications, and outcomes. Semin Thorac Cardiovasc Surg. 2012;24:195-201.

4. Suri RM, Schaff HV, Dearani JA, Sundt TM III, Daly RC, Mullany CJ, et al. Survival advantage and improved durability of mitral repair for leaflet prolapse subsets in the current era. Ann Thorac Surg. 2006;82:819-26.

5. Schäfers HJ, Bierbach B, Aicher D. A new approach to the assessment of aortic cusp geometry. J Thorac Cardiovasc Surg. 2006;132:436-8.

6. Boodhwani M, de Kerchove L, Glineur D, Poncelet A, Rubay J, Astarci P, et al. Repair-oriented classification of aortic insufficiency: impact on surgical techniques and clinical outcomes. J Thorac Cardiovasc Surg. 2009;137:286-94. 
7. Aicher D, Fries R, Rodionycheva S, Schmidt K, Langer F, Schäfers HJ. Aortic valve repair leads to a low incidence of valve-related complications. Semin Thorac Cardiovasc Surg. 2012;24:195-201.

8. Minakata K, Schaff HV, Zehr KJ, Dearani JA, Daly RC, Orszulak TA, et al. Is repair of aortic valve regurgitation a safe alternative to valve replacement? J Thorac Cardiovasc Surg. 2004;127:645-53.

9. Frater RWM. The prolapsing aortic cusp. Ann Thorac Surg. 1967;3:63-7.

10. Cabrol C, Cabrol A, Guiraudon G, Bertrand M. Treatment of aortic insufficiency by means of aortic annuloplasty. Arch Mal Coeur Vaiss. 1966;59:1305-12.

11. Trusler GA, Moes CAF, Kidd BSL. Repair of ventricular septal defect with aortic insufficiency. J Thorac Cardiovasc Surg. 1973;66:394-403.

12. de Heer LM, Budde RP, Mali WP, de Vos AM, van Herwerden LA, Kluin J. Aortic root dimension changes during systole and diastole: evaluation with ECG-gated multidetector row computed tomography. Int J Cardiovasc Imaging. 2011;27:1195-204.

13. Smedira NG, Blackstone EH, Roselli EE, Laffey CC, Cosgrove DM. Are allografts the biologic valve of choice for aortic valve replacement in nonelderly patients? Comparison of explantation for structural valve deterioration of allograft and pericardial prostheses. J Thorac Cardiovasc Surg. 2006;131:558-64.

14. Weber A, Noureddine H, Englberger L, Dick F, Gahl B, Aymard T, et al. Ten-year comparison of pericardial tissue valves versus mechanical prostheses for aortic valve replacement in patients younger than 60 years of age. J Thorac Cardiovasc Surg. 2012;144:1075-83.

15. Saxena A, Poh CL, Dinh DT, Reid CM, Smith JA, Shardey GC, et al. Early and late outcomes after isolated aortic valve replacement in octogenarians: an Australasian Society of Cardiac and Thoracic Surgeons cardiac surgery database study. Eur J Cardiothorac Surg. 2012;41:63-8.

16. Di Eusanio M, Fortuna D, De Palma R, Dell'Amore A, Lamarra M, Contini A, et al. Aortic valve replacement: results and predictors of mortality from a contemporary series of 2256 patients. J Thorac Cardiovasc Surg. 2011;141: 940-7.

17. Ashikhmina E, Sundt TM III, Dearani JA, Connolly HM, Li Z, Schaff HV. Repair of the bicuspid aortic valve: a viable alternative to replacement with a bioprosthesis. J Thorac Cardiovasc Surg. 2010;139:1395-401.

18. Chan V, Malas T, Lapierre H, Boodhwani M, Lam BK, Rubens FD, et al. Reoperation of left heart valve bioprostheses according to age at implantation. Circulation. 2011;124(suppl):S75-80

19. Alsoufi B, Borger MA, Armstrong S, Maganti M, David TE. Results of valve preservation and repair for bicuspid aortic valve insufficiency. $J$ Heart Valve Dis. 2005;14:752-8

20. Aicher D, Schneider U, Schmied W, Kunihara T, Tochii M, Schäfers HJ. Early results with annular support in reconstruction of the bicuspid aortic valve. J Thorac Cardiovasc Surg. 2013;145:S30-4

21. de Kerchove L, Boodhwani M, Glineur D, Vandyck M, Vanoverschelde JL, Noirhomme P, et al. Valve sparing-root replacement with the reimplantation technique to increase the durability of bicuspid aortic valve repair. $J$ Thorac Cardiovasc Surg. 2011;142:1430-8.

22. Tornos P, Sambola A, Permanyer-Miralda G, Evangelista A, Gomez Z, Soler-Soler J. Long-term outcome of surgically treated aortic regurgitation: influence of guideline adherence toward early surgery. J Am Coll Cardiol. 2006;47:1012-7

23. Brown ML, Schaff HV, Suri RM, Li Z, Sundt TM, Dearani JA, et al. Indexed left ventricular dimensions best predict survival after aortic valve replacement in patients with aortic valve regurgitation. Ann Thorac Surg. 2009;87:1170-5.

24. Olsen NT, Sogaard P, Larsson HB, Goetze JP, Jons C, Mogelvang R, et al. Speckle-tracking echocardiography for predicting outcome in chronic aortic regurgitation during conservative management and after surgery. JACC Cardiovasc Imaging. 2011;4:223-30.

\section{Discussion}

Dr Hans-Joachim Schäfers (Homburg/Saar, Germany). I congratulate Dr Suri and his colleagues for the excellent results and the excellent presentation. They have shown that $\mathrm{AVR}_{\mathrm{ep}}$ can be performed with low morbidity and mortality and very good stability, which, at least in the pathologic entities shown here, exceeds the mean durability of a biologic AVR for the age group.
They have identified pathologic entities that seem to benefit more, and, most importantly, they bring up the point of whether we should wait with an operation until LV dysfunction sets in or rather propose surgery before the onset of LV dysfunction. I have 2 comments and 2 questions.

In our experience, the stability of a repaired tricuspid valve significantly exceeds that of a bicuspid valve. You showed different results, although the difference was not statistically significant. Could you elaborate on the reasons for the slightly higher risk of reoperation in tricuspid valves? Was this related to the technique of cusp repair, the technique of annular stabilization, or does it rather reflect the more difficult learning curve of assessing valve configuration in tricuspid aortic valves?

Dr Suri. Thank you, Professor Schäfers, for those questions. This is a curious finding and, as you point out, although we did not demonstrate a statistically significant difference in reoperation rates among the pathologic-anatomic subgroups, we will continue to analyze these data as the available follow-up duration lengthens and the total number of repairs available for analysis increases.

As you know, patients with tricuspid aortic valve prolapse often present at an older age than those with bicuspid regurgitation, and, therefore, we hypothesized that due to the, at times, sclerotic nature of the aortic cusps in the older patients with poor tissue quality, this might have been responsible for the slightly increased raw number of recurrences. That said, with the new echocardiographic tools available, including measurement of both the annulus and the coaptation margins, as you have championed, we hope to further elucidate the predictors of reoperation with greater precision in the future.

Dr Schäfers. You proposed earlier surgery, and one could go as far as proposing surgery for AR similar to that for mitral regurgitation, that is, every severe mitral regurgitation should be repaired. However, we need to remember that this is primarily recommended for mitral pathologic entities, which can be repaired with a likelihood of $90 \%$.

To translate such a concept into the treatment of AR, of course, we need to consider the total number of patients with $A R$ who go to the operating room. In other words, we need to define the denominator. This, of course, is difficult in such a retrospective study. Nevertheless, can you explain or comment on the reasons for exclusion from $\mathrm{AVR}_{\mathrm{ep}}$ and rather the decision for primary AVR?

Dr Suri. The questions are good ones-(1) will $\mathrm{AVR}_{\mathrm{ep}}$ ever have a $99 \%$ success rate, such as mitral valve repair for degenerative leaflet prolapse does in the current era; and (2) will early $\mathrm{AVR}_{\text {ep }}$ ever be enthusiastically endorsed at the guideline level? Several differences between degenerative aortic and mitral disease must be considered when we address these questions. The first 2 differences are technical ones: the first being the relative lack of aortic cusp tissue available, and the second, the rather greater unpredictability of cusp tissue quality compared with that of mitral valve leaflets. We also must acknowledge disparities in knowledge-even if aortic repair were to become more widely available, the heterogeneous historic echocardiographic quantification of aortic valve regurgitation has led to a lag in our understanding of the effect of uncorrected severe AR on longterm survival. It will thus take some time for correction of AR with aortic repair to become widely recognized as an operation 
that should be performed earlier to improve late survival. Even if that were to occur, however, the outcomes might remain less uniform than the enviable results we have seen for degenerative mitral valve disease owing to the important differences in tissue characteristics I mentioned earlier.

Thus, if we had to put things together in moving $\mathrm{AVR}_{\mathrm{ep}}$ forward, our perspective would be as follows. Number 1, as you point out, we need to understand the denominator; in other words, which patients truly have severe aortic insufficiency that is repairable? Number 2, can we more accurately describe, as you and Professor El-Khoury, Dr David, and others in the room have done, the pathoanatomic subgroups we are speaking about to better communicate among centers? Accomplishing these aims will better allow us to standardize repair maneuvers and relate them to the mid- and late-term outcomes. The establishment of international multicenter registries will facilitate a better understanding of how the timing of surgery and surgery type (repair vs replacement) relate to long-term survival, heart failure, and reoperation risks. Ultimately, consensus statements might recommend that $\mathrm{AVR}_{\mathrm{ep}}$ be performed before prognosis-limiting events such as LV dilation or dysfunction, analogous to those relating to mitral valve repair currently. Once again, important in all this is developing good judgment in determining who should undergo $\mathrm{AVR}_{\mathrm{ep}}$ and which patients might be best served by AVR.

Dr Schäfers. What were the exclusion criteria for repair? What made you shy away from repair that you found on the intraoperative transesophageal echocardiography or inspection?

Dr Suri. We would tend favor AVR for patients with calcified cusps that are immobile or retracted or those with poor tissue quality, particularly, if they are elderly.

Dr Schäfers. Thank you. My congratulations for this important study, and I would like to thank the Society for the privilege of discussing it.

Dr Suri. Thank you, Professor Schäfers.

Dr Khalid Rasheed (Karachi, Pakistan). Congratulations for this excellent presentation, but as has been said, there is always room for improvement. It has been recognized that in $\mathrm{AVR}_{\mathrm{ep}}$ or reconstruction the sinotubular junction also has a vital role. In your repair techniques, do you do anything to either stabilize or fix the sinotubular junction so that it does not dilate and lead to valve failure?

Dr Suri. Thank you for the question. I would like to acknowledge our former fellow and now surgical associate, Dr Vikas
Sharma, for diligently combing through these records. In doing so, we have removed all cases of aortic aneurysm pathology from the present analysis, except for those with solely supra-sinotubular junction dilatation, to focus on the performance of $\mathrm{AVR}_{\mathrm{ep}}$ itself. In general, outside of the present series, if the sinotubular junction is dilated, we do downsize it, using an appropriately sized graft. We do not, however, fix the sinotubular junction routinely to a specific dimension and have not noted progressive sinotubular junction dilatation to be the mechanism of repair failure in our experience. Logically, if sinotubular dilatation occurs in conjunction with annular dilatation, we would address the annulus and also downsize the sinotubular junction in the same operation.

Dr Joseph Ladowski ( $F t$ Wayne, Ind). I would like to point out a fairly minor error in your abstract, which raises a more important question, and that is, you state that of the 227 patients available for follow-up, only 47 were taking warfarin and state that that was $16 \%$. It is actually $>20 \%$. That, combined with your reoperation rate of $>20 \%$ at 10 years, leads me to ask, you very elegantly told us which patients you would not repair going into this, but now that you have all this experience, which ones do you wish you had not repaired?

Dr Suri. I think the interpretation might need a little clarification. We actually were speaking about those who underwent $\mathrm{AVR}_{\mathrm{ep}}$ for primary $\mathrm{AR}$ not requiring concomitant nonaortic valve operations. Thus, excluding those who had, for instance, undergone replacement of their tricuspid valve or mitral valve with a mechanical prosthesis, necessitating warfarin anticoagulation, only roughly $20 \%$ of the remaining population was using oral anticoagulation at the last follow-up visit.

The second point is in whom we would consider repair. I think I alluded to that in my previous response, but I will reiterate for clarity. Dr Schaff has performed the greatest number of repairs in the present report. In general, surgeons at Mayo Clinic consider aortic replacement for severe aortic insufficiency in elderly patients and those with diminished cusp mobility, poor tissue quality, or cusp calcification. However, as we have demonstrated in the presentation, the exponential failure rate of bioprosthetic valves in younger patients deserves consideration. AVR in those with a pliable, mobile aortic valve might no longer be the default procedure in the current surgical era, especially for young patients, because experience with $\mathrm{AVR}_{\mathrm{ep}}$ is growing and the overall durability has been demonstrated. 